\title{
Lack of Association between Factor V Leiden G1691A, Prothrombin G20210A, MTHFC677T Mutations, and Early Recurrent Pregnancy Loss in a Group of Sudanese Women
}

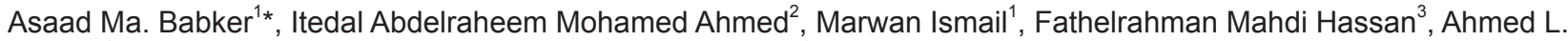 \\ Osman ${ }^{1}$, Praveen Kumar Kandakurti ${ }^{4}$, Abd Elgadir A. Altoum ${ }^{1}$ \\ ${ }^{1}$ Department of Medical Laboratory Sciences, College of Health Sciences, Gulf Medical University, Ajman, United Arab Emirates; \\ ${ }^{2}$ Department of Anatomy, Clinical Anatomy, Embryology, Cell Biology and Health professional Education, College of Medicine, \\ Najran University, Saudi Arabia; ${ }^{3}$ Department of Clinical Laboratory Sciences, College of Applied Medical Science, Imam \\ Abdulrahman Bin Faisal University, Saudi Arabia; ${ }^{4}$ Department of Physiotherapy, College of Health Sciences, Gulf Medical \\ University, Ajman, United Arab Emirates
}

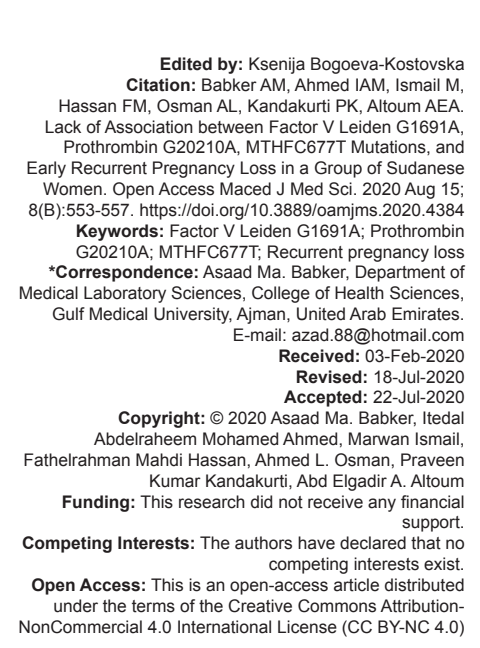

Introduction

Pregnancy loss is defined as the loss of a pregnancy prior to 24 weeks gestation. Recurrent pregnancy loss has previously been defined as three or more pregnancy losses [1].The exact prevalence of RPL is difficult to estimate, but most studies report that RPL affects $1-2 \%$ of women [2]. There are numerous factors that may cause (RPL), but the underlying problem often remains undetected. Although much work has been done to identify the underlying mechanisms, the cause of miscarriage can be identified in only $50 \%$ of cases. The known causes of RPL include chromosomal and metabolic abnormalities, uterine anomalies, thrombophilia and immunologic factors [3]. Thrombophilia has been identified as one of the main causes of RPL with a percentage of $40 \%$, early RPL. Although several studies on this topic are available in the literature to confirm this trend, rates of thrombophilia seem to differ from study to study because of different inclusion criteria and different ethnic backgrounds of the selected patients [4] The contribution of thrombophilias to adverse outcomes in pregnancy is controversial. Studies tend to be small, have population selection bias, and have differences in the diagnostic criteria. Inherited and acquired thrombophilias contribute further to an increased predisposition to thrombotic events. The overall impact of the inherited and acquired thrombophilias is low in the nonpregnant population, 
and most patients never experience a thrombotic event [5]. Hereditary thrombophilia comprises several conditions, such as antithrombin (AT) III deficiency, protein S (PS) and protein C (PC) deficiencies, factor $V$ Leiden, prothrombin 20210A mutation, elevated factor VIII level, and mutation of gene encoding the enzyme methylenetetrahydrofolate reductase (MTHFR) [6]. Factor $\mathrm{V}$ Leiden genetic disorder is characterized by poor response to activated protein C (APC). APC is a natural anticoagulant protein that cleaves and inactivates procoagulant factors $\mathrm{Va}$ and VIIIa, thereby decreasing the formation of thrombin [7]. Prothrombin, or factor II, is the precursor of thrombin. This protein is a vitamin $\mathrm{K}$ dependent zymogen that is produced by the liver and has a central role in the conversion of fibrinogen into fibrin [8].The mutation in prothrombin is associated with an increased plasma concentration of prothrombin, which leads to an increased potential for thrombin generation [9].The MTHFR gene is responsible for the production of the enzyme methylenetetrahydrofolate reductase (MTHFR). A mutation in the gene inhibits the production of this enzyme, result in hyperhomocystinemia and this increase has been associated with poor pregnancy outcomes. Numerous studies have reported associations between Factor $\mathrm{V}$ Leiden G1691A, prothrombin G20210A, MTHFC677T Mutations polymorphisms with poor pregnancy outcomes $[10,11,12]$. This study aimed at testing the association between FVL, FII, MTHFR and RPL in Sudanese women. The frequencies of these mutations was statistically compared among cases with RPL and a control group of healthy women to test whether significant differences in mutation frequencies exist between the two groups.

\section{Methods}

The current study is a retrospective analytical case-control study designed to investigate the relationship between Factor $V$ Leiden G1691A, methylenetetrahydrofolate reductase (MTHFR) C677T and the prothrombin G20210A mutation variant and recurrent pregnancy loss. The study included a hundred Sudanese women who experienced three or more of the adverse pregnancy loss as case group in the Omdurman maternity hospital (Sudan) and they were compared with ninety four healthy women who made up the control group with at least more than two normal pregnancies and without any history of adverse pregnancy outcome or recurrent miscarriages during the period from July 2013 to July 2015. We included each woman who at least three or more consecutive RPL outcomes with unknown caused had and excluded each women had known cause of RPL. After consents were obtained from the patients and control blood samples were collected from participants and total genomic DNA was isolated from blood leukocytes and the frequency of these gene mutations in the patients and controls was determined using PCR-restriction fragment length polymorphism. DNA was extracted from the blood samples using Master pure DNA purification kit for blood GF-1 Blood DNA Extraction Kit, 50 PREPS (cat. No. GF-BD-050, Vivantis Technologies Sdn. Bhd., Malaysia). FV Leiden G1691A, MTHFR C677T and FII. a 345-bp genomic DNA fragment encompassing a part of the prothrombin gene that contains the mutation was amplified by PCR using specific primers Forward (5'TCT AGA AAC AGT TGC CTG GC-3') and Reverse primer (5'ATA GCA CTG GGA GCA TTG AAG C-3). And 267-basepair (bp) segment of the factor $V$ gene was amplified using specific forward primer (5'TCA GGC AGG AAC AAC ACC AT-3') and reverse primer 5'GGT TAC TTC AAG GAC AAA ATA CCT GTA AAG CT3. MTHFR gene by using the site specific primers Forward ( 5' TGA AGG AGA AGG TGT CTG CGG GA-3') and Reverse primers: 5'AGG ACG GTG CGG TGA GAG AGT G -3'. The reaction program was as follows: Denaturation at $94^{\circ} \mathrm{C}$ for 30 seconds, annealing at $51^{\circ} \mathrm{C}$ for 30 seconds, extension at $72^{\circ} \mathrm{C}$ for 30 seconds, 15 for 35 cycles and $72^{\circ} \mathrm{C}$ for 5 minutes. A master mix was prepared by adding Nuclease free water,10x buffer, dNT $P$, tow primers,Mgc 12, Taq DNA polymerase and DNA, the mixture was loaded into thermocycler according to the specific Temperature profile. The working solution of $1 \mathrm{X}$ TBE was prepared from the stock solution $(1 \mathrm{~L})$ which contained the following: $89 \mathrm{mM}$ Tris base $(108 \mathrm{gm}), 89$ $\mathrm{mM}$ boric acid ( $55 \mathrm{gm}) 40 \mathrm{ml}$ of $0.5 \mathrm{M}$ EDTA, adjust $\mathrm{pH}$ to 8.0.1.5\% agarose was prepared from $1 \times$ TBE, and $5 \mu l$ PCR products were loaded by mixing PCR products with $1 \mu$ l loading dye, run on the gel for 30 mins and visualized on UV transilluminator. Factor $\mathrm{V}$ digested with $10 \mu \mathrm{l}$ of DNA restriction enzyme $\mathrm{Mnl} 1$ at $37^{\circ} \mathrm{Cfor}$ $18 \mathrm{~h}$, subjected to $2 \%$ low melting point agarose and Prothrombin product $(10 \mu \mathrm{L})$ was digested with $20 \mathrm{U}$ of Hind III, at $37^{\circ} \mathrm{C}$ for $16 \mathrm{~h}$, and loaded into $2 \%$ low melting point agarose gel, eletropherosed at 90 volts for 60 mins. MTHFC677T was digested by enzyme (Hindfl) by Added $10 \mu \mathrm{l}$ mixtures to the $10 \mu \mathrm{l}$ MTHFR products, a quick spinning is needed, 5- Incubated at $37^{\circ} \mathrm{C} 18$ hours, and the reaction was stopped with 4 $\mu \mathrm{l}$ prom phenol blue dye, then $18 \mu \mathrm{l}$ digested products was loaded into $2 \%$ agarose. Data were statistically described in terms of mean \pm standard deviation ( \pm SD), median and range, or frequencies (number of cases) and percentages where appropriate[13,14]. The odds ratio (OR) and the 95\% confidence interval $(95 \% \mathrm{Cl})$ were calculated for the presence of mutation between cases and controls and analyzed by SPSS program (version: 17.0). Data were analyzed using the Chi-square test to compare the prevalence of MTHFR mutation between patients and controls (The test was considered significant when $p$-value $<0.05)$. Ethical consent was obtained from the ethical committee at Omdurman Maternity Hospital (Sudan). 


\section{Results}

The participants included 194 women subjects. Out of them, 100 had a history of 3 or more events of recurrent fetal loss. Their mean age $\pm S D$ was $25 \pm 4$. Moreover, 94 women were healthy, and their mean age was $30 \pm 4$. (Table 1$)$. Table 1: Distribution of study subjects according to age

\begin{tabular}{llll}
\hline Characteristics & & Patients $\mathrm{n}(\%)$ & Controls $\mathrm{n}(\%)$ \\
\hline Age group & $17-24$ & $10(10.1)$ & $13(13.8)$ \\
& $25-29$ & $29(29.3)$ & $28(29.8)$ \\
& $30-34$ & $27(27.3)$ & $36(38.3)$ \\
& $35-39$ & $21(21.2)$ & $8(8.5)$ \\
& $\geq 40$ & $12(12.1)$ & $9(9.6)$ \\
\hline
\end{tabular}

Maternal age was divided into five major groups $(17-24,25-29,30-34,35-39$, and $\geq 40)$. Abortion rates among these groups were represented by 38 (18.8), 26 (12.9\%), 39 (19.2\%), 40 $(19.8 \%)$, and $59(29.2 \%)$, respectively (Figure 1).

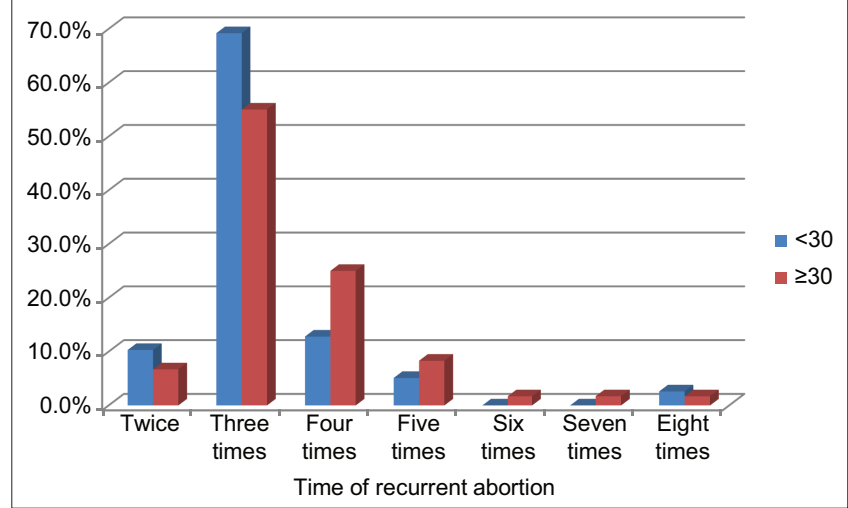

Figure 1: Distribution of recurrent pregnancy loss cases according to age groups

Factor $\mathrm{V}$ Leiden mutation distribution showed a higher prevalence among case group than the control group. Mutation was detected in 8 out of cases $(8.0 \%)$ and in 6 out of 94 of the control group $(6.4 \%)$ p-value $=0.66$, odds ratio $=1.28,95 \% \mathrm{Cl}(0.42-3.84)$. The prevalence of heterozygous FVL mutation in RPL women was found to be $8 \%$, but the control group was found to be $6.4 \%$. Normal homozygous (G/G) among cases showed $92 \%$, but the controls showed $93.6 \%$. Alleles $\mathrm{G}$ allele occurred with a frequency of 96 . \% among cases and $96.8 \%$ in the controls, while mutant allele (A) was seen only in $4 \%$ of the cases. The frequency of a mutant allele (A) was $3.2 \%$ and $G$ allele occurred with a frequency of $96.8 \%$ among controls. According to this result, there is statistically insignificant between the cases and controls group (Table 2). Table 2: Frequency of factor $\mathbf{V}$ (Leiden) mutation among cases of recurrent pregnancy loss compared to controls

\begin{tabular}{lllll}
\hline Genotype & $\begin{array}{l}\text { Patients } \\
\mathrm{n}(\%)\end{array}$ & $\begin{array}{l}\text { Controls } \\
\mathrm{n}(\%)\end{array}$ & $\mathrm{p}$-value & OR $(95 \% \mathrm{Cl})$ \\
\hline Heterozygous G/A & $8(8.0)$ & $6(6.4)$ & 0.66 & $1.28(0.42$ to 3.84$)$ \\
Normal homozygous G/G & $92(92.0)$ & $88(93.6)$ & & \\
Alleles G & $192(96.0)$ & $182(96.8)$ & 0.67 & $0.76(0.27$ to 2.33) \\
Alleles A & $8(4.0)$ & $6(3.2)$ & & \\
\hline
\end{tabular}

The prevalence of the prothrombin gene was $3 \%$ among cases with $p$-value $=0.091$. However, no mutant gene was detected among the control group. According to the genotyping in cases, it showed (heterozygotes, $3.0 \%$ and homozygotes, $97.0 \%)$, alleles G $(98.5 \%)$ and alleles $A(1.5 \%)$, while in the control group, it showed normal homozygous G/G (100\%) and alleles $G$ (alleles $G$ ). There was no significant association between cases carriage any of this mutation and risk with recurrent pregnancy miscarriage (Table 3). Table 3: Frequency of prothrombin mutation among cases of recurrent pregnancy loss compared to controls

\begin{tabular}{lllll}
\hline Genotype & Patients n (\%) & Controls n (\%) & p-value & OR $(95 \% \mathrm{Cl})$ \\
\hline Heterozygous G/A & $3(3.0)$ & 0 & 0.091 & 0 \\
Normal homozygous G/G & $97(97.0)$ & $94(100)$ & & \\
Alleles G & $194(98.5)$ & $188(100)$ & 0.089 & 0 \\
Alleles A & $3(1.5)$ & 0 & & \\
\hline
\end{tabular}

The frequency of heterozygous C/T MTHFR gene was $3.0 \%$ in cases with $p=0.091$; there was no mutant gene detected among the control group. The normal homozygous gene was $97.0 \%$ in cases, and $100 \%$ showed in the control group. The frequency of alleles $\mathrm{C}$ was $98.5 \%$ in cases and $100 \%$ in controls, while alleles $\mathrm{T}$ was $1.5 \%$. There was no significant association between cases carriage any of this mutation and risk of recurrent mistcarriage (Table 4).

Table 4: Frequency of MTHFR mutation among cases of recurrent pregnancy loss compared to controls

\begin{tabular}{lllll}
\hline Genotype & Patients n (\%) & Controls n (\%) & p-value & OR $(95 \% \mathrm{Cl})$ \\
\hline Heterozygous C/T & $3(3.0)$ & 0 & 0.091 & 0 \\
Normal homozygous C/C & $97(97.0)$ & $94(100)$ & & \\
Alleles T & $3(1.5)$ & 0 & 0.089 & 0 \\
Alleles C & $194(98.5)$ & $188(100)$ & & \\
\hline
\end{tabular}

\section{Discussion}

Exploring the relation between Factor $\mathrm{V}$ Leiden, Prothrombin and methylene gene mutation with recurrent pregnancy loss is a challenge. This is because recurrent pregnancy loss has multiple etiologies, where genetic factors are considered as one of those etiologies. Advance technology in molecular genetics provides an accurate and reliable tool to precisely study the genetic abnormalities associated with recurrent pregnancy loss and several studies have identified thrombophilia genes mutation as the principal cause of recurrent pregnancy loss. The present study is the first to report the frequency of inherited thrombophilia (Factor $\mathrm{V}$ Leiden G1691A, prothrombin G20210A and MTHFC677T) together among the same group of Sudanese patients with recurrent pregnancy loss. The results obtained in this study are in accordance with the results of previous research, and indicate that the MTHFR C677T, FVL, and FII G20210A polymorphisms are not associated with recurrent pregnancy loss, Fátima et al. [15], had investigated 100 women with three or more consecutive miscarriages and concluded that neither FVL nor PT G20210A is associated with RM prior to 10 weeks of gestation. Other large prospective studies reported contradictory results stating that hypercoagulable 
thrombophilic gene mutations are not increased in women with recurrent miscarriage [16], [17]. In another study conducted by Henry et.al, [18], they confirmed the low prevalence of inherited thrombophilias in nonCaucasian populations and it is unlikely that the tested thrombophilias play a role in the pathogenesis of recurrent pregnancy loss in this Colombian population. They are also congruent with another study conducted by Abu-Asab et al., they did not find a significant association between FVL, FII, and MTHFR and RPL in the first and second trimester [19]. Our results are in contrast to another previous recurrent pregnancy loss studies that found a positive association between Factor V Leiden G1691A, prothrombin G20210A, MTHFC677T mutations and recurrent pregnancy loss. Tawfik et al. had found MTHFR C667T, Factor V Leiden and prothrombin gene mutations are significantly increased in patients having recurrent miscarriages [20]. Another study conducted among Syrian women by W Al-Achkar et.al, indicate that RPL women with homozygous genotype for (C677T and A1298C) either alone or compound heterozygous genotypes have a high risk of pregnancy loss in Syrian women [21]. Another study conducted in northern area of Saudi Arabia among spontaneous miscarriage women by Fakhr-Eldeen et.al, concludes that FVL and PTH gene mutations, but not MTHFR were significantly prevalent and associated with RSM in the study population [22]. In Sudan some previous studies had investigated the frequency of these genes' mutation but among people with other disorders not RPL, like deep venous thrombosis and the finding are varying [23], [24].The variation in findings could be explained by the differences in ethnicity, the study sample size and design as well as the other interacting genetic and environmental factors that affect the final thrombophilic phenotype of the RPL patients [25]. Exploring the relation between Factor $V$ Leiden. Prothrombin and methylene gene mutation with recurrent pregnancy loss is a challenge. Several studies have identified thrombophilia as the principal cause of recurrent pregnancy loss [26]. However, reported studies often do not evaluate other causes of RPL in their inclusion and exclusion criteria. In addition, many authors suggest that methodological diversity, sample size and clinical heterogeneity may have a role in this discrepancy and contradiction.

\section{Conclusion}

We conclude that the low prevalence of factor V Leiden, prothrombin G20210A, and MTHFC677T in Sudanese women with RPL does not play a role in the pathogenesis of recurrent pregnancy loss among our population. Furthermore, larger-scale studies are required to clarify the association between these variants and RPL and their role in this condition.

\section{Acknowledgments}

The authors would like to thank the women who were involved in the study, the midwives, and the nursing staff of the Omdurman Maternity Hospital for their cooperation.

\section{References}

1. Li YH, Marren A. Recurrent pregnancy loss. Aust J Gen Pract. 2018;47(7):432.

PMid:30114870

2. Atik RB, Christiansen OB, Elson J, Kolte AM, Lewis S, Middeldorp S, et al. ESHRE Guideline: Recurrent Pregnancy Loss. United States: ESHRE Guideline Group on RPL; 2018.

3. Grimstad F, Krieg S. Immunogenetic contributions to recurrent pregnancy loss. J Assisted Reprod Genet. 2016;33(7):833-47. https://doi.org/10.1007/s10815-016-0720-6

PMid:27169601

4. D'Uva M, Di Micco P, Strina I, De Placido G. Recurrent pregnancy loss and thrombophilia. J Clin Med Res. 2010;2(1):18.

PMid:22457696

5. Battinelli EM, Marshall A, Connors JM. The role of thrombophilia in pregnancy. Thrombosis. 2013;2013:9. https://doi.org/10.1155/2013/516420

6. Giovanni L, Antonio AP, Danilo C, Stefano G, Therese D, Elisabetta RM, et al. Thrombophilias and pregnancy complications: A case-control study. Int J Biomed Sci. 2007;3(3):168 PMid:23675040

7. Ruiz LG, Oliveira MG, Ruiz AL, Daher CS, Nogueira ML. Hereditary thrombophilia by factor $V$ Leiden G1691A (heterozygous) and FII prothrombin G20210A (homozygous) mutations in a patient with ischemic cerebrovascular accident. J Bras Patol Med Lab. 2018;54(2):92-4. https://doi. org/10.5935/1676-2444.20180016

8. Nguyen A. Prothrombin G20210A polymorphism and thrombophilia. Mayo Clin Proc. 2000;75(6):595-604. https://doi. org/10.4065/75.6.595

9. Abdullah WZ, Kumaraguru S, Ghazali S, Yusoff NM. Factor V Leiden and prothrombin G20210A mutations among healthy Indians in Malaysia. Lab Med. 2010;41(5):284-7. https://doi. org/10.1309//m9w9l8gqpczvayo

10. Long S, Goldblatt J. MTHFR genetic testing: Controversy and clinical implications. Aust Fam Physician. 2016;45(4):237. PMid:27052143

11. IvyAAA, Louis MA. The 5, 10 methylenetetrahydrofolatereductase C677T mutation and risk of fetal loss: A case series and review of the literature. Thromb J. 2007;5:17.

PMid: 17941987

12. Al-Achkar W, Wafa A, Ammar S, Moassass F, Jarjour RA Association of methylenetetrahydrofolate reductase C677T and A1298C gene polymorphisms with recurrent pregnancy loss in Syrian women. Reprod Sci. 2017;24(9):1275-9. https://doi. org/10.1177/1933719116682874 PMid:28814189

13. Serrano F, Lima ML, Lopes C, Almeida JP, Branco J. Factor V Leiden and prothrombin G20210A in portuguese women with recurrent miscarriage: Is it worthwhile to investigate? Arch Gynecol Obstetr. 2011;284(5):1127-32. https://doi.org/10.1007/ 
s00404-010-1834-1

PMid:21259017

14. Roque $\mathrm{H}$, Paidas MJ, Funai EF. Maternal thrombophilias are not associated with early pregnancy loss. Thromb Haemost. 2004;91(2):290. https://doi.org/10.1160/th03-09-0596 PMid:14961156

15. Clark P, Walker ID, Govan L. The GOAL study: A prospective examination of the impact of factor $V$ Leiden and $A B O$ blood groups on haemorrhagic and thrombotic pregnancy outcomes. $\mathrm{Br} J$ Haematol. 2008;140(2):236. https://doi. org/10.1111/j.1365-2141.2007.06902.x

PMid:18028481

16. Cardona H, Castañeda SA, Maya WC, Alvarez L, Gómez J, Gómez J, et al. Lack of association between recurrent pregnancy loss and inherited thrombophilia in a group of Colombian patients. Thrombosis. 2012;2012:367823. https:// doi.org/10.1155/2012/367823

PMid:22577540

17. Abu-Asab NS, Ayesh SK, Ateeq RO, Nassar SM, El-Sharif WA. Association of inherited thrombophilia with recurrent pregnancy loss in palestinian women. Obstetr Gynecol Int. 2011;2011:6. https://doi.org/10.1155/2011/689684

18. Abdelsalam T, Karkour T, Elbordiny M, Shalaby D, Abouzeid ZS.
Thrombophilia gene mutations in relation to recurrent miscarriage. Int J Reprod Contracept Obstet Gynecol 2018;7:796-800. https:// doi.org/10.18203/2320-1770.jircog20180857

19. Badawy A, AISel BA, Fawzy MS. Factor V Leiden G1691A and prothrombin G20210A mutations are associated with repeated spontaneous miscarriage in Northern area of Saudi Arabia. Genet Mol Res. 2017;16(4):16039810. https://doi.org/10.4238/ gmr16039810

20. Alfeel $\mathrm{AH}$. Association of Factor V-Leiden and Prothrombin G20210A Mutations wth Deep Venous Thrombosis in Patients Attending Khartoum Hospitals, Khartoum State, Sudan (20132016), Doctoral Dissertation. Sudan: University of Gezira; 2016.

21. Awad-Elkareem A, Elzaki SG, Khalid H, Abdallah MS, Adam I. A low rate of factor $V$ Leiden mutation among Sudanese women with deep venous thrombosis during pregnancy and puerperium. J Obstetr Gynaecol. 2017;37(7):963-4. https://doi.org/10.1080/0 1443615.2017.1306033

PMid:28395587

22. Awad NS, Almalki TA, Sabry AM, Mohamed AA, Said MM, El-Tarras AE. Screening of factor V G1691A (Leiden) and factor II/prothrombin G20210A polymorphisms among apparently healthy taif-Saudi Arabia population using a reverse hybridization strip assay approach. World J Med Sci 2013;9(4):202-7. 